\title{
Age-related sex differences in the expression of important disease-linked mitochondrial proteins in mice
}

\author{
Michael Moschinger ${ }^{1 \dagger}$, Karolina E. Hilse ${ }^{1 \dagger}$, Anne Rupprecht ${ }^{1,2}$, Ute Zeitz ${ }^{1}$, Reinhold G. Erben ${ }^{1}$, Thomas Rülicke ${ }^{3}$ and
} Elena E. Pohl ${ }^{1 *}$ (D)

\begin{abstract}
The prevalence and progression of many illnesses, such as neurodegenerative and cardiovascular diseases, obesity, and cancer, vary between women and men, often in an age-dependent manner. A joint hallmark of these diseases is some type of mitochondrial dysfunction. While several mitochondrial proteins are known to be regulated by sex hormones, the levels of those proteins have not been systematically analyzed with regard to sex and age, and studies that consider sex and/or age differences in the protein expression are very rare. In this study, we compared the expression patterns of physiologically important mitochondrial proteins in female and male C57BL/6N mice of age cohorts frequently used in experiments. We found that sex-related differences in the expression of uncoupling proteins 1 and 3 (UCP1 and UCP3) occur in an age-dependent manner. The sex-specific expression of UCP1 and UCP3 in brown adipose tissue (BAT) was inversely correlated with differences in body weight. Expression of UCP4 in the brain, Complex I in the spleen, and Complex II in the brain and BAT was least affected by the sex of the mouse. We further demonstrated that there are serious limitations in using VDAC1 and actin as markers in western blot analyses, due to their sex- and age-specific fluctuations. Our results confirm that sex and age are important parameters and should be taken into account by researchers who examine the mechanistic aspects of diseases.
\end{abstract}

\section{Highlights:}

I. The levels of UCP1 and UCP3 protein expression differ between females and males in an age-dependent manner.

II. Pre-pubertal expression of almost all proteins tested in this study does not depend on the sex of the mouse.

III. Expression of VDAC1 and actin, which are often used as loading control proteins in western blot analysis, is tissue-specifically influenced by sex and age.

\section{Introduction}

In recent years, sex-based differences have become more apparent in the pathogenesis, progression, and treatment outcomes of various human diseases, including diabetes, obesity, and cardiovascular disease, as well as autoimmune and neurological dysfunction $[1,2]$. The factors thought to contribute to these sex-based differences in pathophysiology of various diseases are related to sex

\footnotetext{
* Correspondence: elena.poh|@vetmeduni.ac.at

${ }^{\dagger}$ Michael Moschinger and Karolina E. Hilse contributed equally to this work. 'Institute of Physiology, Pathophysiology and Biophysics, Department of Biomedical Sciences, University of Veterinary Medicine, Vienna, Austria
} Full list of author information is available at the end of the article chromosomes, miRNAs, different levels of circulating steroid hormones (estrogen, androgens, and progesterone), nutrition, microbiota, and anatomical differences [3-9]. The global expression of sex hormone receptors in cells suggests that their influence on gene expression is higher than previously assumed [4]. However, biomedical research is often biased because potential sex differences are not accounted for in a study's design and data analysis [10]. Sex bias is especially prominent in the field of neuroscience, due to the prevalent assumption that sex does not influence the physiology of the nervous system $[11,12]$.

(c) The Author(s). 2019 Open Access This article is distributed under the terms of the Creative Commons Attribution 4.0 International License (http://creativecommons.org/licenses/by/4.0/), which permits unrestricted use, distribution, and reproduction in any medium, provided you give appropriate credit to the original author(s) and the source, provide a link to the Creative Commons license, and indicate if changes were made. The Creative Commons Public Domain Dedication waiver (http://creativecommons.org/publicdomain/zero/1.0/) applies to the data made available in this article, unless otherwise stated. 
Sex hormone receptors (e.g., estrogen receptors) are localized in the mitochondria of certain cells and influence mitochondrial physiology [13]. Additionally, it was reported that sex hormones can affect the expression of mitochondrial proteins encoded by either mitochondrial (mtDNA) or nuclear DNA $[14,15]$. mtDNA is exclusively inherited from a mother in most mammals. Several mitochondrial proteins, especially mitochondrial outer membrane protein voltage-dependent anion channel 1 (VDAC1), are often used as a quantitative control in western blot (WB) analyses [16, 17]. However, their sex- and age-specific expression has been poorly investigated, and the lack of knowledge in this area can lead to erroneous conclusions in various studies. Earlier, an agedependent decrease in the expression of cytosolic proteins that are routinely used as loading controls, such as glyceraldehyde 3-phosphate dehydrogenase (GAPDH), $\alpha$ tubulin, and $\beta$-actin, in skeletal muscles (SkM) was already reported [18], suggesting that these proteins might be altered in an age-dependent manner in human tissues.

The mouse is a popular model for studying human diseases because (i) of its small size and rapid reproduction, (ii) its genome shares $85 \%$ identity with the human genome [19], (iii) many of its physiological systems function in manner similar to those in humans, and (iv) loss- and gain-of-function mutations are relatively easy to introduce into the mouse genome [20]. The genotype and phenotype of the inbred strain C57BL/6N have been well-characterized and the strain is frequently used as background for the generation of genetically modified mouse models. Sex-specific factors such as fluctuating sex hormone levels in female mice and strong fighting behavior in male mice often lead to a decision to use only one sex in biomedical studies [11].

Here, we examined the influence of sex on the expression of essential mitochondrial proteins in $\mathrm{C} 57 \mathrm{BL} / 6 \mathrm{~N}$ mice at different life stages. We investigated three main protein groups that included (i) respiratory chain proteins Complex I (CI), Complex II (CII), and ATP synthase (CV), (ii) mitochondrial uncoupling proteins (UCP1-UCP4), and (iii) VDAC1 in the brain, SkM, brown adipose tissue (BAT), and spleen. Additionally, we compared the expression of two cytosolic proteins ( $\alpha$ - and $\beta$-actin), which are often used as loading controls in WB analyses.

\section{Materials and methods}

\section{Animals and standard preparation}

Female and male C57BL/6NRj (B6) mice (ages 1, 5, and 10 months) in SPF quality were housed in a rodent facility (photoperiod $12 \mathrm{~L} / 12 \mathrm{D}$, temperature $22.0{ }^{\circ} \mathrm{C} \pm 2.0{ }^{\circ} \mathrm{C}$ ). Food and water were available ad libitum and the mice were fed with a commercial regular mouse diet (ssniff Spezialdiäten $\mathrm{GmbH}$, Germany). Mice were maintained in groups in polycarbonate cages (Type IIL, Tecniplast, Italy) lined with bedding material (Lignocel ${ }^{\oplus}$, heat treated, Rettenmaier KG, Austria) and enriched with nesting material (Pur-Zellin $4 \times 5 \mathrm{~cm}$; Paul Hartmann $\mathrm{GmbH}$, Austria). For dissection and tissue sampling, the animals were weighed and then sacrificed by inhalation of a mixture of $79 \% \mathrm{CO}_{2}$ and $21 \% \mathrm{O}_{2}$ until breathing arrest, and then decapitated. For the quantification of all western blot results, tissue standards were produced from pooled $(n=$ 10-20) B6 mice of different ages for each sex.

\section{Western blot analysis}

WB analysis was performed as previously described [21, 22]. Briefly, samples of the brain, BAT, SkM (gastrocnemius muscle), and spleen tissue were homogenized in RIPA buffer (50 mM Tris; $150 \mathrm{mM}$ sodium chloride; $1 \mathrm{mM}$ EDTA; $1 \%$ sodium deoxycholate; $1 \%$ Triton X-100; $0.1 \%$ sodium dodecyl sulfate; pH 7.4) supplemented with a protease inhibitor cocktail (Sigma-Aldrich). The homogenates were then sonicated and centrifuged at $1000 \mathrm{~g}$ for $10 \mathrm{~min}$ at $4{ }^{\circ} \mathrm{C}$. Next, the supernatants were centrifuged again at $2.500 \mathrm{~g}$ for $10 \mathrm{~min}$ at $4{ }^{\circ} \mathrm{C}$. The total protein concentration was determined using a Pierce ${ }^{\mathrm{Tm}}$ BCA Protein Assay Kit (Thermo Scientific, Waltham, MA, USA). Twenty micrograms for brain tissue and BAT and $50 \mu \mathrm{g}$ for spleen and SkM (gastrocnemius muscle, GMsc) tissue were separated by SDS-PAGE. The separated protein bands were then transferred onto membranes that were incubated overnight at $4{ }^{\circ} \mathrm{C}$ with primary antibodies against UCP1 (1:1000, U6382, SigmaAldrich, Additional file 1: Figure S1A), UCP2 (evaluated in [23] Additional file 1: Figure S1B), UCP3 (evaluated in [21], Additional file 1: Figure S1C), UCP4 (evaluated in [24], Additional file 1: Figure S1D), subunit NDUFA9 of CI (1:3000, 459100, Invitrogen, Additional file 1: Figure. S2A), subunit SDHA of CII (1:7500, Ab14715, Abcam, Additional file 1: Figure. S2B), subunit beta of ATP synthase (1:5000, A21351, Invitrogen, Additional file 1: Figure S2, C), VDAC1 (1:5000, Ab14734, Abcam, Additional file 1: Figure S2D), $\alpha$ actin (1:5000, Ab88226, Abcam, Additional file 1: Figure S2, E), and $\beta$-actin (1:10000, A5441, Sigma-Aldrich, Additional file 1: Figure S2, F); after which, the membranes were incubated with a secondary antibody that was conjugated with horseradish peroxidase. The immunostained protein bands were detected by chemiluminescence, and intensity of staining was quantified by using Launch Vision Works LS software. Examples of whole WB images are shown in Additional file 1: Figures S1 and S2 illustrating the protein bands against a protein ladder. The relative amount of each protein was calculated as the ratio of the staining intensity of the target protein band vs. the loaded standard band. 


\section{Statistical analysis}

Data from WB analyses are presented as the mean value \pm SD of results obtained from at least two independent experiments (samples from 6 mice per sex and age). All data were analyzed using the two-sided $t$ test and the twosided one-way ANOVA test, and $p$ values $<0.05$ were considered to be statistically significant. The symbols * and \#, ** and \#\#, or ${ }^{* * * *}$ and \#\#\# indicate statistically significant $p$ values of $<0.05,<0.01$, and $<0.001$, respectively.

\section{Results}

Influence of sex and age on the expression of key mitochondrial proteins in the brain tissue

To evaluate whether the distribution of physiologically relevant mitochondrial proteins in the brain tissue differed between females and males, we evaluated the protein levels of UCP4; electron transport chain (ETC) proteins $\mathrm{CI}, \mathrm{CII}$, and $\mathrm{CV}$; outer mitochondrial membrane protein VDAC1, and non-mitochondrial protein $\beta$-actin in pre-pubertal (1-month-old), pubertal (5month-old), and post-pubertal (10-month-old) B6 mice of different sex at physiological conditions. Our results showed that all tested proteins were expressed at similar levels in male and female pre-pubertal mice (Fig. 1a-f). CII, ATP synthase, and UCP4 (Fig. 1b, c, e) did not show sexspecific expression at any of the life stages. CI, CV, VDAC1, UCP4, and $\beta$-actin were influenced by age. The greatest variations were found for $\mathrm{CI}$ (Fig. 1a; Additional file 1: Figure S4A) and VDAC1 (Fig. 1d and Additional file 1: Figure S4B) protein levels, and those two proteins showed similar expression patterns. Five-month-old female mice exhibited two-fold higher levels of $\mathrm{CI}$ and VDAC1 expression when compared with male mice (Table 1). In addition, both of those proteins displayed two-fold increases in expression from childhood to maturity in both sexes. Surprisingly, the level of $\beta$-actin expression (Fig. 1f) in post-pubertal mice declined by $50 \%$ when compared to $\beta$-actin expression in pre-pubertal mice, and the decline was not sex-specific.

\section{Influence of sex and age on the expression of key mitochondrial proteins in BAT}

BAT has been shown to be an important target for treating obesity $[25,26]$. Because metabolic activity and nonshivering thermogenesis in BAT were described to be sex-specific [27, 28], we compared the expression levels of certain mitochondrial proteins (ETC complexes, VDAC1, UCP1, and UCP3) and a cytoskeletal protein $(\alpha$-actin). Our results confirmed that all those proteins were similarly expressed in pre-pubertal mice (Fig. 2ag). Furthermore, we did not detect any sex differences in the levels of CII and ATP synthase expression in postpubertal mice (Fig. 2b, c). An age-dependent increase in VDAC1 expression coupled with a sex dimorphism was observed in 5- and 10-month-old mice (Fig. 2d).
However, this sex dimorphism most greatly affected the levels of UCP1 and UCP3 expression in the 10-monthold mice (Fig. 2e, f and Additional file 1: Figure S4C). A time course of UCP1 expression showed a decrease in 5month-old mice, followed by an increase at 10 months, and the increase was $33 \%$ greater in female mice. The levels of UCP3 expression were also increased in female mice at the age of 10 months and were approximately two-fold higher than those in male mice. Surprisingly, UCP3 expression in male mice declined with age. The level of $\alpha$-actin expression was increased by $33 \%$ in 5 month-old female mice (Fig. 2g).

\section{Influence of sex and age on the expression of key mitochondrial proteins in SkM}

To evaluate whether metabolically relevant mitochondrial proteins in SkM displayed a sex-dependent pattern of expression, we measured the expression of mitochondrial ETC complexes, VDAC1, and UCP3, as well as a cytoskeletal protein ( $\alpha$-actin) as described above. Figure $3 a-f$ demonstrates that the pre-pubertal expression of the measured proteins was similar in both sexes, with the exception that CII and ATP synthase showed slightly higher levels of expression in females than in males. While CII and ATP synthase exhibited hardly any sex-related differences at post-puberty, they did show age-dependent changes (Fig. 3b, c). CI showed a sex-specific decrease in both male and female mice at the age of 10 months (Fig. 3a). VDAC1 expression was sex-specific at the age of 10 months and showed the tendency to decline in both sexes (Fig. 3d). UCP3 abundance was strongly sex-dependent in 5-month-old animals and was three-fold higher in males (Fig. 3e). Male mice displayed an age-dependent decline in UCP3 expression, whereas UCP3 expression in females was decreased at the age of 5 months compared to 1month-old mice and significantly increased again at the age of 10 months compared to the 5-month-old mice. An age-dependent decline in $\alpha$-actin levels was also observed in both sexes but was more intense in males (Fig. 3f and Additional file 1: Figure S4D).

\section{Influence of sex and age on the expression of key mitochondrial proteins in the spleen}

Immune response in the context of infectious diseases, cancer, and autoimmunity is known to be influenced by sex in an age-specific manner [2]. To test whether this phenomenon was reflected in the levels of various mitochondrial proteins, we evaluated the expression of $\mathrm{CI}$, CII, ATP synthase, VDAC1, and UCP2, as well as expression of the cytoskeletal protein $\beta$-actin. Once again, the pre-pubertal levels of expression for all those proteins were similar in both sexes, with the exception of CII (Fig. 4a-f). Moreover, the post-pubertal expression patterns of $\mathrm{CI}, \mathrm{UCP} 2$, and $\beta$-actin 

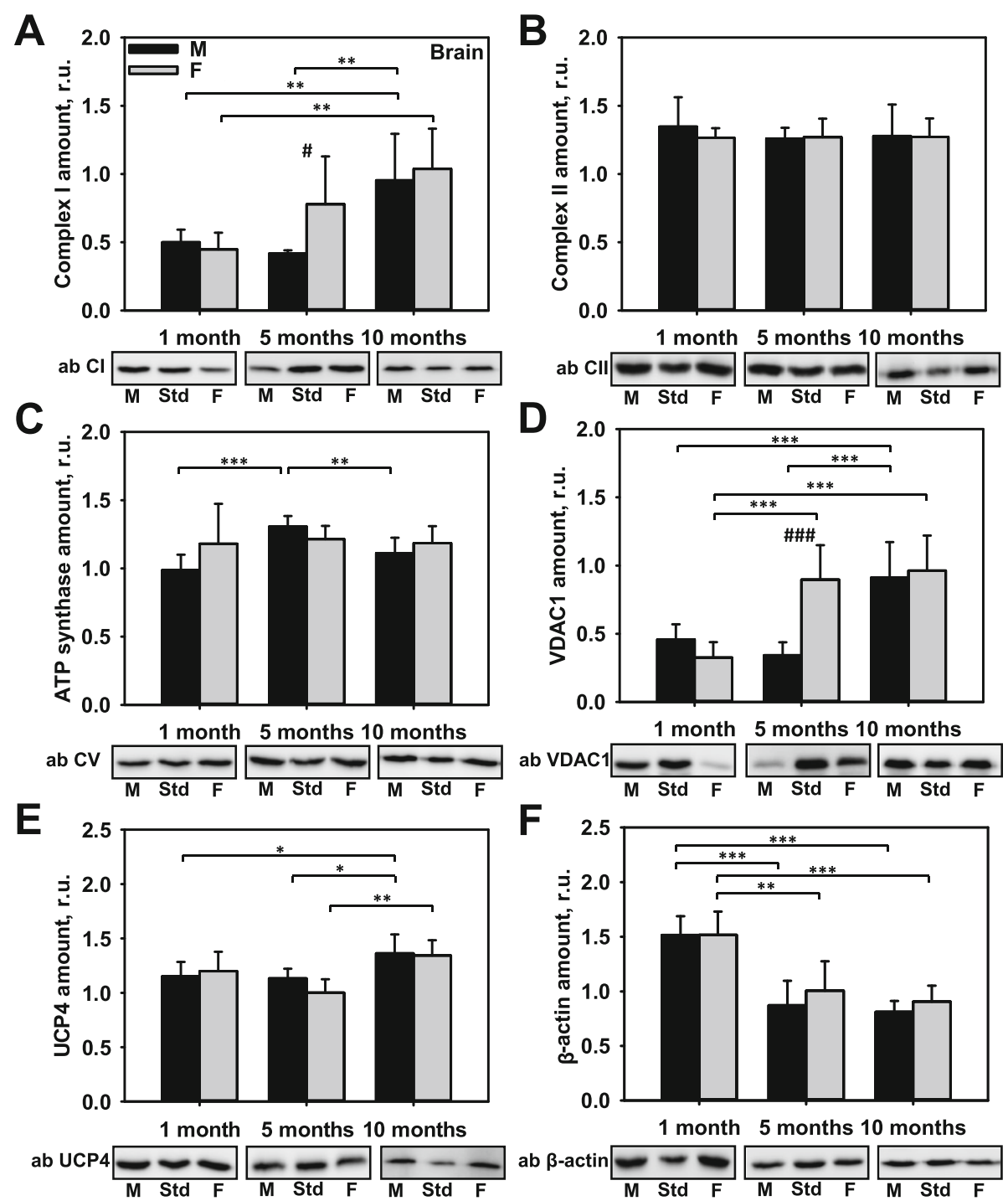

Fig. 1 Comparison of protein expression in the brain tissues of female and male mice. Quantitative analysis of western blot (WB) images obtained from 1, 5, and 10-month-old female (F) and male (M) mice showing the relative amounts of Complex I (a), Complex II (b), ATP synthase (c), VDAC1 (d), UCP4 (e), and $\beta$-actin (f) as compared to a brain tissue standard (Std). Representative WB images are shown below the plots. $20 \mu \mathrm{g}$ of total protein were loaded in each lane. Values represent the means \pm SD of data obtained from six animals per group; ${ }^{*} p<0.05,{ }^{* *} p<0.01$, and ${ }^{* *} p<0.001$ (mark age differences); $\# p<0.05$, \#\#p $<0.01$, and \#\#\#p 0.001 (mark sex differences)

were similar in mice of both sexes (Fig. 4a, e, f). Surprising results were obtained for ATP synthase expression. Here, we observed a strong increase in ATP synthase levels at the age of 10 months, and the levels were two-fold higher in female mice (Fig. 4c and Additional file 1: Figure S4E). A sex dimorphism was detected in the expression pattern of VDAC1 in 5-month-old animals, which was two-fold higher in male mice (Fig. 4d). In contrast, the time course of VDAC1 expression in female mice remained constant over time.

\section{Discussion}

When using standardized, wild-type B6 mice as an animal model, we found that the levels of UCP1 and UCP3 protein expression in male and female mice differed in an age-dependent manner, whereas the expression of UCP4 was similar in both sexes. Protein expression of ETC members has shown tissues-specific differences between males and females: CII and ATP synthases were similarly abandoned in the brain and BAT, CI expression was not influenced by sex and age in the spleen (see Table 1 for summary). We further demonstrated that VDAC1 and actin, which are regularly used as reference proteins in WB analyses, are tissue-specifically influenced by sex and age.

Few studies have investigated the sex-specific expression of proteins, and the existing studies have usually 
Table 1 Summary of sex differences in the protein expression of Complex I (CI), Complex II (CII), ATP synthase (CV), VDAC1, UCP1, UCP2, UCP3, UCP4, a-actin, and $\beta$-actin measured in the brain, brown adipose tissue (BAT), skeletal muscle (SkM), and spleen tissue. Protein expression was compared between female and male mice at an age of one $(1 \mathrm{~m})$, five $(5 \mathrm{~m})$ and ten months $(10 \mathrm{~m})$ and is presented as ratios female/male (red) or male/female (blue). n. a. stands for not applicable. " "-" indicates no or very small difference (1

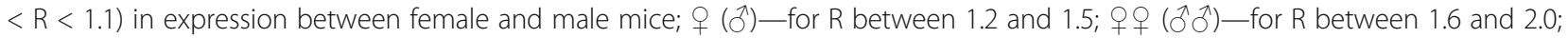

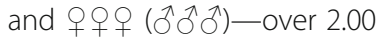

\begin{tabular}{|c|c|c|c|c|c|c|c|c|c|c|c|c|}
\hline & \multicolumn{3}{|c|}{ Brain } & \multicolumn{3}{|c|}{ BAT } & \multicolumn{3}{|c|}{ SkM } & \multicolumn{3}{|c|}{ Spleen } \\
\hline & $1 \mathrm{~m}$ & $5 \mathrm{~m}$ & $10 \mathrm{~m}$ & $1 \mathrm{~m}$ & $5 m$ & $10 \mathrm{~m}$ & $1 \mathrm{~m}$ & $5 m$ & $10 \mathrm{~m}$ & $1 \mathrm{~m}$ & $5 \mathrm{~m}$ & $10 \mathrm{~m}$ \\
\hline CI & - & 우우 & - & - & q & q & - & - & q & - & - & - \\
\hline CII & - & - & - & - & - & - & 우 & - & q & $\delta$ & $\lambda$ & - \\
\hline $\mathrm{CV}$ & q & - & - & - & - & $\hat{\sigma}$ & 우 & $\delta$ & - & $\delta$ & q & 우우 \\
\hline VDAC1 & $\hat{\sigma}$ & 우우우 & - & 우 & 우 & $\hat{\sigma}$ & - & $\hat{\partial}$ & 우 & - & $\hat{\partial} \hat{0}$ & - \\
\hline UCP1 & \multicolumn{3}{|c|}{ n. a. } & - & q & q & \multirow{2}{*}{\multicolumn{3}{|c|}{$\begin{array}{l}\text { n. a. } \\
\text { n. a. }\end{array}$}} & \multicolumn{3}{|c|}{ n. a. } \\
\hline UCP2 & & n. a. & & \multicolumn{3}{|c|}{ n. a. } & & & & $\pi$ & - & - \\
\hline UCP3 & & n. a. & & - & - & 우우 & - & $\hat{\partial} \partial \hat{\sigma}$ & - & \multirow{2}{*}{\multicolumn{3}{|c|}{$\begin{array}{l}\text { n. a. } \\
\text { n. a. }\end{array}$}} \\
\hline UCP4 & - & - & - & \multicolumn{3}{|c|}{ n. a. } & \multicolumn{3}{|c|}{ n. a. } & & & \\
\hline$\alpha$-actin & & n. a. & & - & q & - & - & - & 우우우 & \multicolumn{3}{|c|}{ n. a. } \\
\hline$\beta$-actin & - & q & - & & n. a. & & & n. a. & & - & 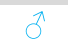 & - \\
\hline
\end{tabular}

focused on only one tissue [11]. Moreover, in most studies, age groups are arbitrarily chosen, and only one age is usually tested for a specific condition. Here, we compared for the first time the expression patterns of physiologically important mitochondrial proteins in female and male B6 mice. To reflect a wide variety of scientific conditions, we tested frequently used age cohorts: 1,5 , and 10 months, respectively. These age choices reflect the physiologically important stages of murine life, such as pre-puberty, puberty, and adulthood. Our data showed that almost all the candidate proteins were expressed at similar levels in both sexes at a pre-pubertal age. However, significant sex differences become apparent in adulthood. Impressive sex dimorphisms were observed for two members of the mitochondrial uncoupling protein family, UCP1 and UCP3. These proteins showed a tendency for decreased expression with age in male mice, whereas, in females, we observed a decline in their expression at the age of 5 months, followed by an upregulation at 10 months. Several studies have provided evidence that the UCP family may be regulated by sex hormones [28-30]; however, their results are contradictory and/or based only on mRNA data or an analysis of one tissue type. It was previously shown that because of the unusually short half-life and strong post-translational regulation of UCP2 and UCP3 [31-33], a determination of their protein levels (and not mRNA levels) is the only accurate way to perform a functional analysis of these proteins $[21,23,34]$. Our results concerning UCP1 and UCP3 expression relate to age- and sex-dependent changes in body weight (Additional file 1: Figure S3).
The male mice in this study showed a significant increase in body weight with increasing age, whereas we observed only a slight increase in body weight of the female mice (Additional file 1: Figure S3). Notably, the female mice expressed higher levels of UCP1 and UCP3 in their BAT. Results obtained by using models of UCP3 gain-of-function and UCP3 loss-of-function have suggested that UCP3 helps protect against triglyceride accumulation in murine SkM $[35,36]$. Therefore, the upregulation of UCP3 in females may prevent the occurrence of obesity-induced secondary disorders such as cardiovascular diseases and diabetes. The sex-specific expression of UCP1 and UCP3 could explain the different propensities of female and male rodents for becoming obese, and imply that a similar mechanism could exist in humans.

We observed that the protein expression of $\mathrm{CI}$ in the female brain was significantly higher at 5 months than in pre-pubertal and aged mice. In agreement with it, a study of Gaignard et al. (2015) showed that the NADHlinked respiration of isolated brain mitochondria was significantly higher in 3-month-old female mice compared to males and ovariectomized female mice [37]. Arias-Reyes et al. (2019) showed that the NADH-linked respiration in 3-months-old B6 mice is sex-dependent but the NADH-linked respiration in the brain stem and cortex was higher in male mice [38]. More in-depth research is needed to clarify the role of sex influences on the mitochondrial respiration and expression of ETC proteins in the different regions of the brain. 

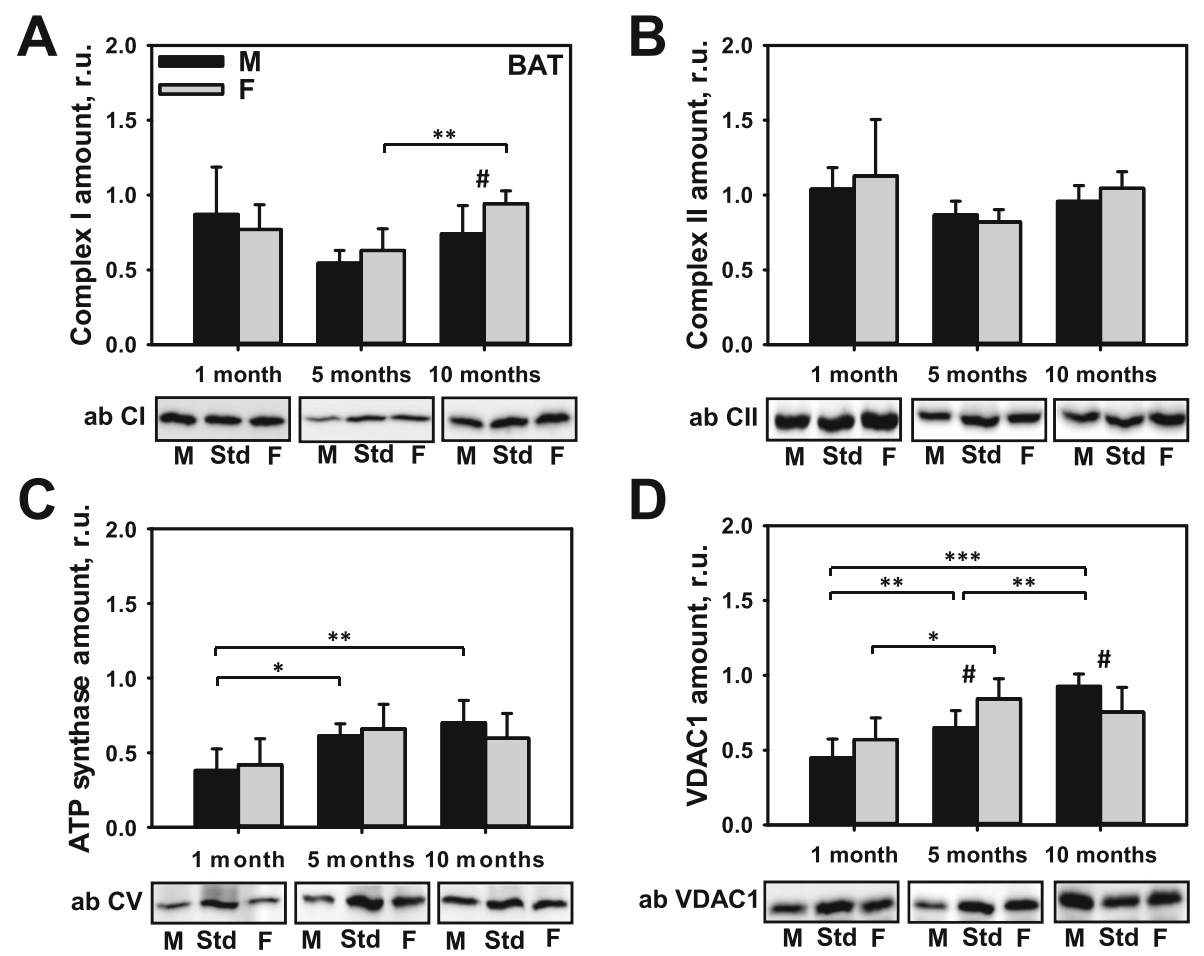

D

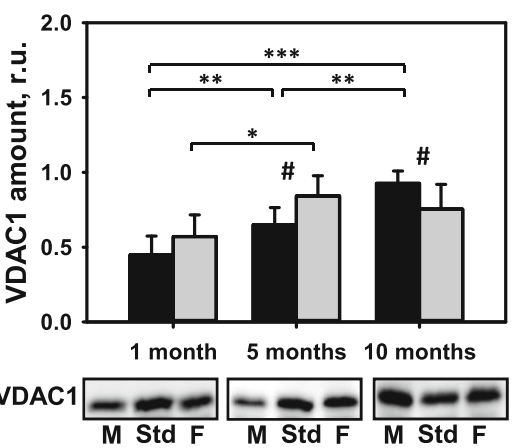

E

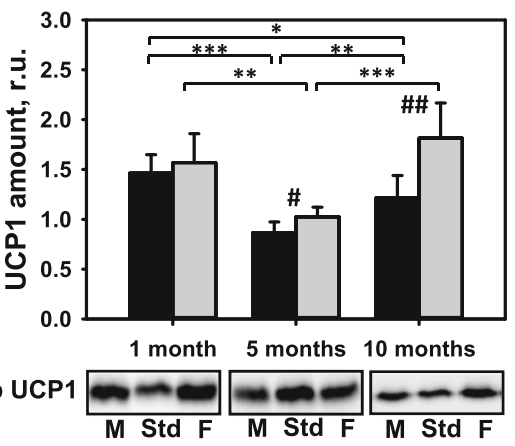

F
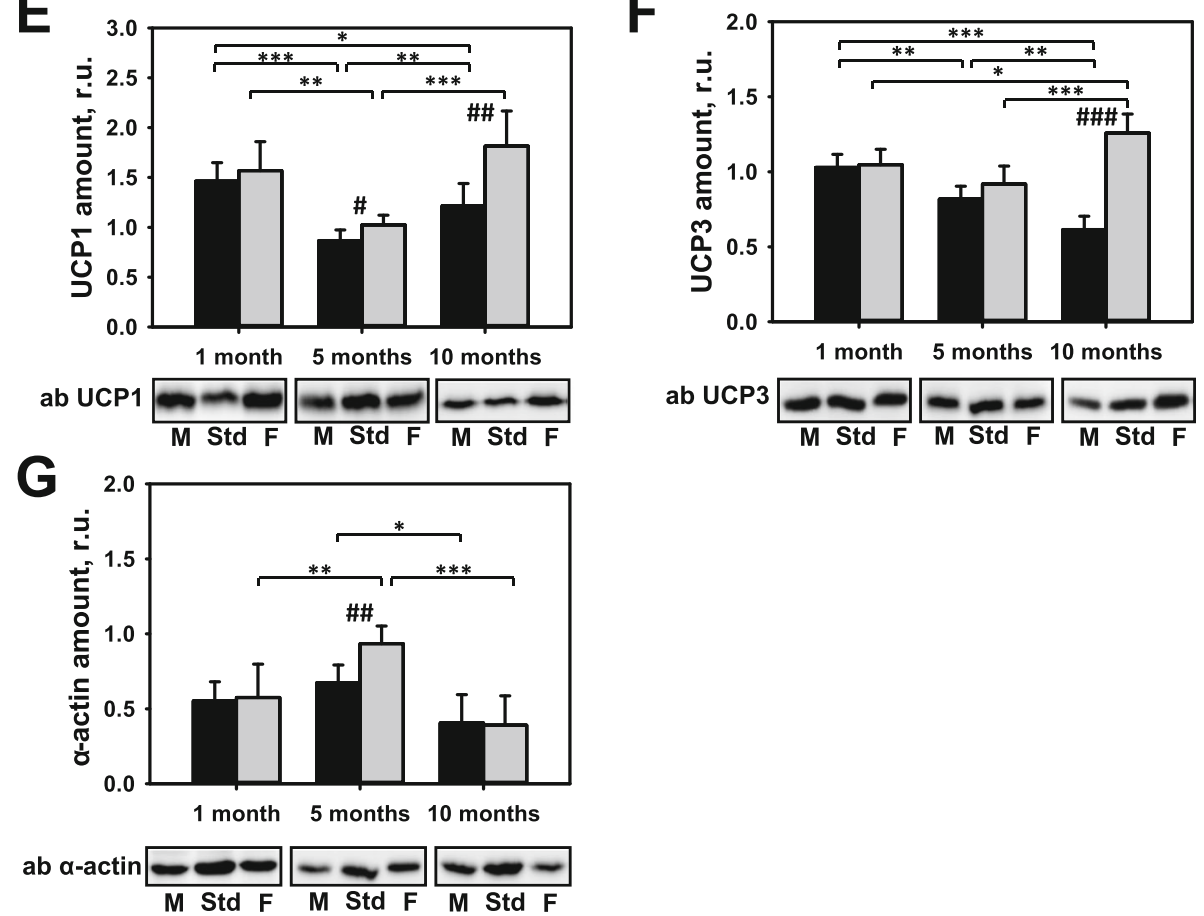

Fig. 2 Comparison of protein expression in brown adipose tissue (BAT) from female and male mice. A quantitative analysis of western blot (WB) images obtained from 1, 5, and 10-month old female (F) and male (M) mice showing the relative amounts of Complex I (a), Complex II (b), ATP synthase $(\mathbf{c}), \operatorname{VDAC1}(\mathbf{d}), \mathrm{UCP} 1(\mathbf{e}), \mathrm{UCP} 3(\mathbf{f})$, and a-actin $(\mathbf{g})$ as compared to a BAT tissue standard (Std). Representative WB images are shown below the plots. $20 \mu \mathrm{g}$ of total protein were loaded in each lane. Values represent the means \pm SD of data obtained from six animals per group;

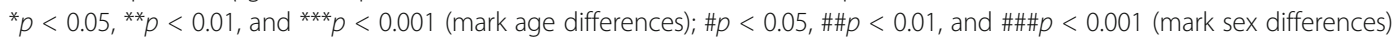



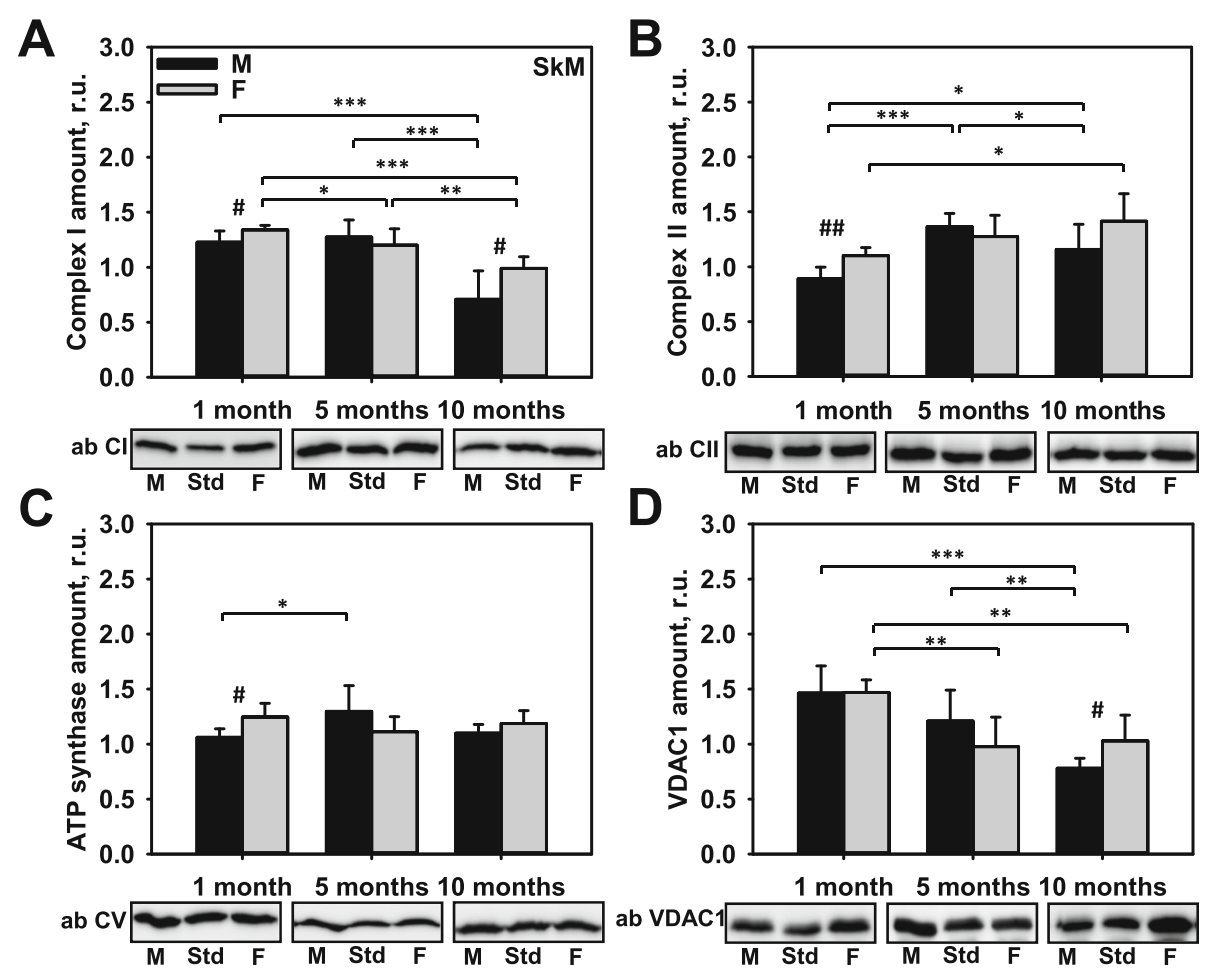

E

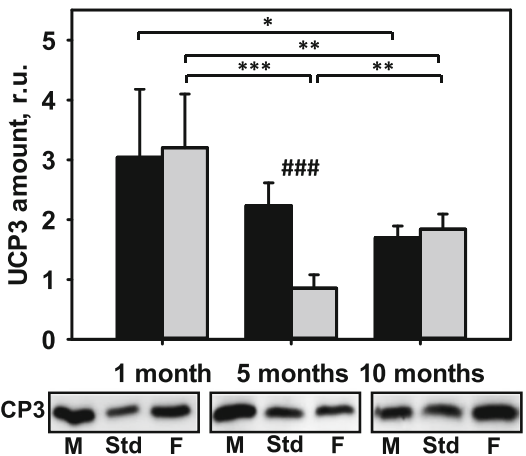

$\mathbf{F}$

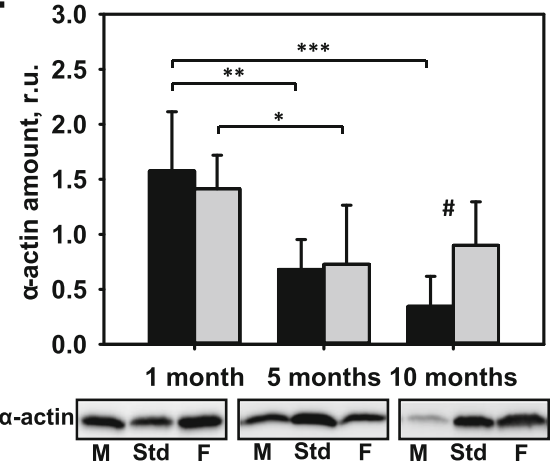

Fig. 3 Comparison of protein expression in skeletal muscle (SkM) from female and male mice. A quantitative analysis of western blot (WB) images obtained from 1, 5, and 10-month old female (F) and male (M) mice showing the relative amounts of Complex I (a), Complex II (b), ATP synthase (c), VDAC1 (d), UCP3 (e), and a-actin (f) as compared to a SkM tissue standard (Std). Representative WB images are shown below the plots. $50 \mu \mathrm{g}$ of total protein was loaded in each lane. Values represent the means \pm SD of data obtained from six animals per group; ${ }^{*} p<0.05,{ }^{* *} p<0.01$, and ${ }^{* * *} p<0.001$ (mark age differences); \#p $<0.05$, \#\# $<0.01$, and \#\# $p<0.001$ (mark sex differences)

The question of whether VDAC1 undergoes sex dimorphisms is very important because in the positive case, it would detract from its often used as a reference protein. Here, we revealed for the first time that the post-pubertal levels of VDAC1 were affected by sex and age in all the analyzed tissues. In contrast, the levels of CII and ATP synthase expression were similar in female and male mice in the brain and BAT. This finding supports data that were obtained by an analysis of $\mathrm{CI}-\mathrm{CV}$ genes in rats; namely no sexual dimorphism in genes that encode for proteins involved in oxidative phosphorylation in hearts of young and adult rats [39]. However, slight tissue-specific sex differences were detected in old mice. We found that ATP synthase was expressed at two-fold higher levels in the spleens of 10-month-old female mice; however, the expression was highly variable among the individual females tested (Additional file 1: Figure S4, E). It is possible that the deviations in ATP expression result from inflammatory processes (e.g., due to the activation of immune cells) that require different metabolic program [40].

Remarkably, we found that expression of the oftenused cytoskeletal marker actin differed in the BAT, SkM, and brain tissues of males and females, and significantly declined with age. Our results support those reported in past studies concerning age-dependent decreases of $\beta$ - 

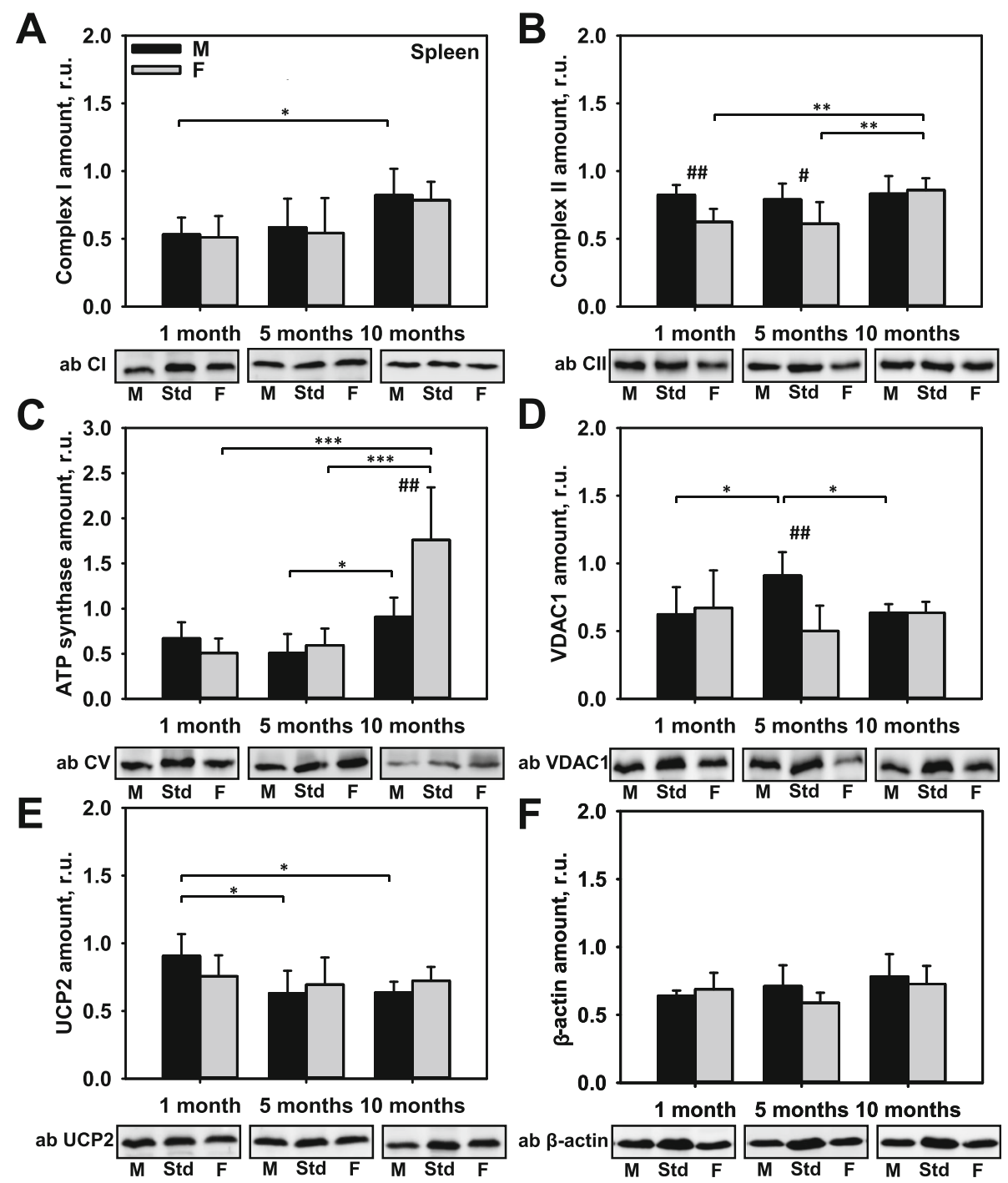

Fig. 4 Comparison of protein expression in spleen tissue from female and male mice. A quantitative analysis of western blot (WB) images obtained from 1, 5, and 10-month old female (F) and male (M) mice showing the relative amounts of Complex I (a), Complex II (b), ATP synthase (c), VDAC1 (d), UCP2 (e), and $\beta$-actin (f) as compared to a spleen tissue standard (Std). Representative WB images are shown below the plots. 50 $\mu \mathrm{g}$ of total protein was loaded in each lane. Values represent the means \pm SD of data obtained from six animals per group; ${ }^{*} p<0.05$, ${ }^{* *} p<0.01$, and ${ }^{* * *} p<0.001$ (mark age differences); \#p $<0.05$, \#\#p $<0.01$, and \#\#\#p 0.001 (mark sex differences)

actin in human SkM [18] and rat brain tissue [41]. It is important to emphasize that the use of conditionally expressed reference proteins for data normalization can result in different interpretations of study results. In one of our previous studies [42], the ratio of UCP4 to VDAC1 protein levels in murine brain tissue showed a decrease in UCP4 expression with increasing age, whereas the ratio of UCP4 to $\beta$-actin showed an increase in UCP4 expression. Both results were repeatable and verified in the current study (Additional file 1: Figure S5). However, the level of UCP4 expression was the same in all groups when it was not compared to a reference protein or normalized to an equally expressed loading control such as CII. This example convincingly demonstrates that the interpretation of experimental data obtained by using different housekeeping proteins can differ when factors such as sex and age are involved in a study. We identified CI (spleen), CII (brain and BAT), and UCP4 (brain) as the loading control proteins that showed the least degree of fluctuation (Table 1). Therefore, they could most likely serve as a reliable control in WB studies that compare different sex and/or age groups. $\beta$-actin showed a constant level of expression in the spleen tissue. $\mathrm{CI}$, VDAC1, and $\alpha$-actin displayed sex and age-specific variations in expression in most tissues. Thus, their use as loading controls should be carefully considered in experiments that compare sex or age groups of B6 mice. 


\section{Significance and perspectives}

The evaluation of sex- and age-dependent differences in the expression of several important mitochondrial proteins will help scientists consider sex or age dimorphisms in their future research. Our results highlight pronounced age-dependent differences in the expression of UCP1 and UCP3 that is especially important in the pathogenesis of obesity, diabetes, and cardiovascular diseases. Dissipating the excess of energy via uncoupling of the oxidative phosphorylation in brown adipocytes is a possible way to prevent overweight [43-45]. The nutritional environment and genetic background can activate the expression of UCPs in brite adipose tissue within white adipose tissue by adrenergic stimulation also in an adult organism. Understanding the regulation mechanism of UCP1/UCP3 and their exact role within the mitochondria inner membrane will provide new strategies to treat obesity and its related diseases.

\section{Supplementary information}

Supplementary information accompanies this paper at https://doi.org/10. 1186/s13293-019-0267-1

Additional file 1: Figure S1. Whole WB images showing the expression of (A) UCP1 in BAT of one-month-old female (F1) and male (M1) mice; (B) UCP2 in the spleen of one-month-old female and male mice; (C) UCP3 in SkM of one-month-old female and male mice; and (D) UCP4 in the brain of five-month-old female and male mice compared to a tissue standard (Std). The protein ladder is illustrated on the left side of the images. The red rectangles mark the height of the individual protein bands Figure S2. Whole WB images showing the expression of $\mathrm{Cl}(\mathrm{A}), \mathrm{CI}(\mathrm{B})$ and $\mathrm{a}-$ actin (E) in SkM of one-month-old female (F1) and male (M1) mice; and CV (C), VDAC1 (D) and ab $\beta$-actin (F) in brain of five-month-old female (F5) and male (M5) mice compared to a tissue standard (Std). The protein ladder is illustrated on the left side of the images. The red rectangles mark the height of the individual protein bands. Additional bands visible on the membranes are pre-stained proteins after stripping Figure S3. Body weight of one, five, and ten-months-old female (F) and male (M) mice. Values represent the means \pm SD of data obtained from six animals per group; ${ }^{* * *} p<0.001$ Figure S4. Box plots diagrams to illustrate variable data points within the expression of (A) $\mathrm{Cl}$ (from Fig. 1, A) and (B) VDAC1 (from Fig. 1, D) in brain; (C) UCP1 (from Fig. 2, E) in BAT; (D) aactin (from Fig. 3, F) in SkM and (E) CV (from Fig. 4, C) in spleen of one, five and ten-months-old males (M1, M5, M10) and females (F1, F5, F10). The boundaries of the box represent $25 \%-75 \%$ of the values. The continuous line represents the median; and the dotted line represents the mean. The highest and lowest values are indicated by the whiskers Figure S5. Comparison of UCP4 protein expression in brain tissue from female and male mice. A quantitative analysis of WB images obtained from one, five, and ten-month old female $(F)$ and male (M) mice showing the relative amounts of UCP4 normalized to VDAC1 (A) or normalized to $\beta$-actin (B). Values represent the means \pm SD of data obtained from six animals per group; ${ }^{*} p<0.05$, ${ }^{* *} p<0.01$, and ${ }^{* *} p<0.001$ (mark age differences); \# $p<0.05$ and \#\# $p<0.01$ (mark sex differences)

\section{Acknowledgements}

We are grateful to Sarah Bardakji (Institute of Physiology, Pathophysiology and Biophysics, University of Veterinary Medicine, Vienna, Austria) for the excellent technical assistance.

\section{Authors' contribution}

$\mathrm{EEP}, \mathrm{MM}$, and $\mathrm{KH}$ conceived the project, designed experiments, and wrote the manuscript. MM performed experiments and analyzed data. EEP, $K H, A R$, and TR contributed to the data interpretation. TR, UZ, and RGE provided age- specific C57BL/6NRj mice. EEP acquired funding and supervised the work. $\mathrm{MM}, \mathrm{KH}$, and EEP wrote the manuscript. All authors edited the final version of the manuscript. All authors read and approved the final manuscript.

Funding

This work was partly supported by Austrian Science Fund (FWF, P25357-820 to EP).

\section{Availability of data and materials}

The datasets used and/or analyzed during the current study are available from the corresponding author on reasonable request.

Ethics approval and consent to participate

Not applicable.

Consent for publication

Not applicable

\section{Competing interests}

The authors declare no competing interests.

\section{Author details}

${ }^{1}$ Institute of Physiology, Pathophysiology and Biophysics, Department of Biomedical Sciences, University of Veterinary Medicine, Vienna, Austria. ${ }^{2}$ Institute of Pharmacology and Toxicology, Rostock University Medical Center, Rostock, Germany. ${ }^{3}$ Institute of Laboratory Animal Science, Department of Biomedical Sciences, University of Veterinary Medicine, Vienna, Austria.

Received: 18 June 2019 Accepted: 17 October 2019

Published online: 05 December 2019

References

1. Whitacre CC. Sex differences in autoimmune disease. Nat Immunol. 2001; 2(9):777-80. https://doi.org/10.1038/ni0901-777.

2. Klein SL, Flanagan KL. Sex differences in immune responses. Nat Rev Immunol. 2016;16(10):626-38. https://doi.org/10.1038/nri.2016.90.

3. Arnold S, Victor MB, Beyer C. Estrogen and the regulation of mitochondrial structure and function in the brain. J Steroid Biochem Mol Biol. 2012;131(12):2-9. https://doi.org/10.1016/j.jsbmb.2012.01.012

4. Wizemann TM, Pardue M-L. Exploring the biological contributions to human health: does sex matter? National Academies Press; 2001.

5. Libert $C$, Dejager L, Pinheiro I. The $X$ chromosome in immune functions: when a chromosome makes the difference. Nat Rev Immunol 2010;10:8:594604; doi:https://doi.org/10.1038/nri2815.

6. Pinheiro I, Dejager L, Libert C. X-chromosome-located microRNAs in immunity: might they explain male/female differences? The $X$ chromosomegenomic context may affect X-located miRNAs and downstream signaling, thereby contributing to the enhanced immune response of females. Bioessays. 2011;33(11):791-802. https://doi.org/10.1002/bies.201100047.

7. Markle JG, Frank DN, Mortin-Toth S, Robertson CE, Feazel LM, RolleKampczyk $U$, et al. Sex differences in the gut microbiome drive hormonedependent regulation of autoimmunity. Science. 2013;339(6123):1084-8. https://doi.org/10.1126/science.1233521

8. Bouman A, Heineman MJ, Faas MM. Sex hormones and the immune response in humans. Hum Reprod Update. 2005;11(4):411-23. https://doi. org/10.1093/humupd/dmi008.

9. Popkov VA, Plotnikov EY, Silachev DN, Zorova LD, Pevzner IB, Jankauskas SS, et al. Diseases and aging: gender matters. Biochemistry (Mosc). 2015;80(12): 1560-70. https://doi.org/10.1134/S0006297915120032.

10. Holdcroft A. Gender bias in research: how does it affect evidence based medicine? J R Soc Med. 2007:100(1):2-3. https://doi.org/10.1258/jrsm.100.1.2.

11. Beery AK, Zucker I. Sex bias in neuroscience and biomedical research. Neurosci Biobehav Rev. 2011;35(3):565-72. https://doi.org/10.1016/j. neubiorev.2010.07.002

12. Luders E, Gaser C, Narr KL, Toga AW. Why sex matters: brain size independent differences in gray matter distributions between men and women. J Neurosci. 2009:29(45):14265-70. https://doi.org/10.1523/ JNEUROSCI.2261-09.2009. 
13. Yang SH, Liu R, Perez EJ, Wen Y, Stevens SM Jr, Valencia T, et al. Mitochondrial localization of estrogen receptor beta. Proc Natl Acad Sci U S A. 2004;101(12):4130-5. https://doi.org/10.1073/pnas.0306948101.

14. Razmara A, Sunday L, Stirone C, Wang XB, Krause DN, Duckles SP, et al. Mitochondrial effects of estrogen are mediated by estrogen receptor alpha in brain endothelial cells. J Pharmacol Exp Ther. 2008:325(3):782-90. https:// doi.org/10.1124/jpet.107.134072.

15. Velarde MC. Mitochondrial and sex steroid hormone crosstalk during aging. Longev Healthspan. 2014;3:1:2; doi:https://doi.org/10.1186/2046-2395-3-2.

16. Hodge T, Colombini M. Regulation of metabolite flux through voltagegating of VDAC channels. J Membr Biol. 1997;157(3):271-9. https://doi.org/ $10.1007 / 5002329900235$.

17. Lee AC, Zizi M, Colombini M. Beta-NADH decreases the permeability of the mitochondrial outer membrane to ADP by a factor of 6. J Biol Chem. 1994; 269(49):30974-80.

18. Vigelso A, Dybboe R, Hansen CN, Dela F, Helge JW, Guadalupe Grau A. GAPDH and beta-actin protein decreases with aging, making stain-free technology a superior loading control in Western blotting of human skeletal muscle. J Appl Physiol (1985). 2015;118:3:386-94; doi:https://doi.org/ 10.1152/japplphysiol.00840.2014.

19. Mouse Genome Sequencing C, Waterston RH, Lindblad-Toh K, Birney E, Rogers J, Abril JF, et al. Initial sequencing and comparative analysis of the mouse genome. Nature. 2002;420:6915:520-62; doi:10.1038/nature01262.

20. Piret SE, Thakker RV. Mouse models for inherited endocrine and metabolic disorders. J Endocrinol. 2011;211(3):211-30. https://doi.org/10. 1530/JOE-11-0193.

21. Hilse KE, Kalinovich AV, Rupprecht A, Smorodchenko A, Zeitz U, Staniek K, et al. The expression of UCP3 directly correlates to UCP1 abundance in brown adipose tissue. Biochim Biophys Acta. 2016;1857(1):72-8. https://doi. org/10.1016/j.bbabio.2015.10.011

22. Hilse KE, Rupprecht A, Egerbacher M, Bardakji S, Zimmermann L, Wulczyn AEMS, et al. The expression of uncoupling protein 3 coincides with the fatty acid oxidation type of metabolism in adult murine heart. Front Physiol. 2018;9:747. https://doi.org/10.3389/fphys.2018.00747.

23. Rupprecht A, Brauer AU, Smorodchenko A, Goyn J, Hilse KE, Shabalina IG, et al. Quantification of uncoupling protein 2 reveals its main expression in immune cells and selective up-regulation during T-cell proliferation. PLoS One. 2012;7:8:e41406; doi:https://doi.org/10.1371/journal.pone.0041406.

24. Smorodchenko A, Rupprecht A, Fuchs J, Gross J, Pohl EE. Role of mitochondrial uncoupling protein 4 in rat inner ear. Mol Cell Neurosci. 2011; 47(4):244-53. https://doi.org/10.1016/j.mcn.2011.03.002.

25. Betz MJ, Enerback S. Targeting thermogenesis in brown fat and muscle to treat obesity and metabolic disease. Nat Rev Endocrinol. 2018;14(2):77-87. https://doi.org/10.1038/nrendo.2017.132.

26. Peirce V, Carobbio S, Vidal-Puig A. The different shades of fat. Nature. 2014; 510(7503):76-83. https://doi.org/10.1038/nature13477.

27. Rodriguez AM, Roca P, Bonet ML, Pico C, Oliver P, Palou A. Positive correlation of skeletal muscle UCP3 mRNA levels with overweight in male, but not in female, rats. Am J Physiol Regul Integr Comp Physiol. 2003;285(4): R880-R8. https://doi.org/10.1152/ajpregu.00698.2002.

28. de Morentin PBM, González-García I, Martins L, Lage R, Fernández-Mallo D, Martínez-Sánchez N, et al. Estradiol regulates brown adipose tissue thermogenesis via hypothalamic AMPK. Cell metabolism. 2014:20(1):41-53.

29. Pedersen SB, Bruun JM, Kristensen K, Richelsen B. Regulation of UCP1, UCP2, and UCP3 mRNA expression in brown adipose tissue, white adipose tissue and skeletal muscle in rats by estrogen. Biochem Biophys Res Commun. 2001;288(1):191-7. https://doi.org/10.1006/bbrc.2001.5763.

30. Rodriguez E, Monjo M, Rodriguez-Cuenca S, Pujol E, Amengual B, Roca P, et al. Sexual dimorphism in the adrenergic control of rat brown adipose tissue response to overfeeding. Pflugers Arch. 2001;442(3):396-403. https:// doi.org/10.1007/s004240100556

31. Rousset S, Mozo J, Dujardin G, Emre Y, Masscheleyn S, Ricquier D, et al. UCP2 is a mitochondrial transporter with an unusual very short half-life. FEBS Lett. 2007:581(3):479-82. https://doi.org/10.1016/j.febslet.2007.01.010.

32. Donadelli M, Dando I, Fiorini C, Palmieri M. UCP2, a mitochondrial protein regulated at multiple levels. Cell Mol Life Sci. 2014;71(7):1171-90. https://doi. org/10.1007/s00018-013-1407-0

33. Rupprecht A, Moldzio R, Modl B, Pohl EE. Glutamine regulates mitochondrial uncoupling protein 2 to promote glutaminolysis in neuroblastoma cells. Biochim Biophys Acta Bioenerg. 2019;1860(5):391-401. https://doi.org/10. 1016/j.bbabio.2019.03.006.
34. Rupprecht A, Sittner D, Smorodchenko A, Hilse KE, Goyn J, Moldzio R, et al. Uncoupling protein 2 and 4 expression pattern during stem cell differentiation provides new insight into their putative function. PLoS One. 2014;9:2:e88474; doi:https://doi.org/10.1371/journal.pone.0088474.

35. Costford SR, Chaudhry SN, Crawford SA, Salkhordeh M, Harper ME. Longterm high-fat feeding induces greater fat storage in mice lacking UCP3. Am J Physiol Endocrinol Metab. 2008;295(5):E1018-24. https://doi.org/10.1152/ ajpendo.00779.2007.

36. Aguer C, Fiehn O, Seifert EL, Bezaire V, Meissen JK, Daniels A, et al. Muscle uncoupling protein 3 overexpression mimics endurance training and reduces circulating biomarkers of incomplete beta-oxidation. FASEB J. 2013; 27(10):4213-25. https://doi.org/10.1096/fj.13-234302.

37. Gaignard P, Savouroux S, Liere P, Pianos A, Therond P, Schumacher M, et al. Effect of sex differences on brain mitochondrial function and its suppression by ovariectomy and in aged mice. Endocrinology. 2015;156(8):2893-904. https://doi.org/10.1210/en.2014-1913.

38. Arias-Reyes C, Losantos-Ramos K, Gonzales M, Furrer D, Soliz J. NADH-linked mitochondrial respiration in the developing mouse brain is sex-, age- and tissue-dependent. Respir Physiol Neurobiol. 2019;266:156-62. https://doi.org/ 10.1016/j.resp.2019.05.011.

39. Vijay V, Han T, Moland CL, Kwekel JC, Fuscoe JC, Desai VG. Sexual dimorphism in the expression of mitochondria-related genes in rat heart at different ages. PLoS One. 2015;10:1:e0117047; doi:https://doi.org/10.1371/ journal.pone.0117047.

40. Buck MD, Sowell RT, Kaech SM, Pearce EL. Metabolic instruction of immunity. Cell. 2017:169(4):570-86. https://doi.org/10.1016/j.cell.2017.04.004.

41. Nishibayashi S, Ogawa N, Asanuma M, Kondo Y, Mori A. Tubulin and actin mRNAs in the young-adult and the aged rat brain: effects of repeated administration with bifemelane hydrochloride. Arch Gerontol Geriatr. 1994; 19(3):265-72. https://doi.org/10.1016/0167-4943(94)00572-9.

42. Smorodchenko A, Rupprecht A, Sarilova I, Ninnemann O, Brauer AU, Franke $\mathrm{K}$, et al. Comparative analysis of uncoupling protein 4 distribution in various tissues under physiological conditions and during development. Biochim Biophys Acta. 2009;1788(10):2309-19. https://doi.org/10.1016/j.bbamem. 2009.07.018.

43. Kozak LP, Anunciado-Koza R. UCP1: its involvement and utility in obesity. Int J Obes (Lond). 2008:32(Suppl 7):S32-S8. https://doi.org/10.1038/ijo.2008.236.

44. Busiello RA, Savarese S, Lombardi A. Mitochondrial uncoupling proteins and energy metabolism. Front Physiol. 2015;6:36. https://doi.org/10.3389/fphys. 2015.00036

45. Hesselink MK, Mensink M, Schrauwen P. Human uncoupling protein-3 and obesity: an update. ObesRes. 2003;11(12):1429-43. https://doi.org/10.1038/ oby.2003.192.

\section{Publisher's Note}

Springer Nature remains neutral with regard to jurisdictional claims in published maps and institutional affiliations.

Ready to submit your research? Choose BMC and benefit from:

- fast, convenient online submission

- thorough peer review by experienced researchers in your field

- rapid publication on acceptance

- support for research data, including large and complex data types

- gold Open Access which fosters wider collaboration and increased citations

- maximum visibility for your research: over $100 \mathrm{M}$ website views per year

At $\mathrm{BMC}$, research is always in progress.

Learn more biomedcentral.com/submission 